\title{
UN studies new science and technology fund
}

Keen to avoid an impasse at the United Nations Conference on Science and Technology for Development when it meets in Vienna next month, UN officials are studying the idea of setting up a new mechanism to support activities meeting the goals established by the conference in a way that is acceptable to both developed and developing nations.

The Group of 77 which is currently negotiating such issues on behalf of over 120 developing countries, has already proposed that an international 'financing system' for science and technology for development be established by the UN, largely financed by the developed nations and aimed to grow to $\$ 2,000$ million by 1985 , and $\$ 4,000$ million by 1990 .

Many developed countries, however, have pointed out the political difficulties that they would face in committing themselves to such a fund, both in terms of the size of the contributions involved, and the form in which it is proposed that they be made - namely as 'automatic' contributions assessed, for example, as a percentage of the balance of trade in manufactured goods with the developing countries.

What is now being sought is a formula that might eventually lead to a transfer of funds for scientific and technological activities of the same order of magnitude as the Group of 77 have proposed, but in a form which would be politically acceptable to the countries expected to be the major donors.

A possible way in which this could be done, according to one line of argument now being actively pursued in the UN and elsewhere, is through an initially relatively modest financial allocation - perhaps in the order of $\$ 250$ million to $\$ 300$ million which could both provide some immediate additional support for science and technology activities and establish the basis for exploring the desirability and feasibility of scaling up to the higher budget levels.

The need to increase the finance for science and technology in development has been emphasized in a paper presented to the UNCSTD secretariat by the United Nations Development Programme. One of the suggestions made in this paper is that the conference should examine and, if appropriate, establish "international arrangements to generate and channel additional funds to developing countries .... to stimulate research and development activities in priority areas."

The UNDP suggests, for example, setting up an international financing facility which, at the request of a particular country, would support selected research projects in key areas, as well as the development, field testing, pilot production and dissemination "which are so essential in the conversion of research into widespread practice""
Such a facility, it says, would aim to ensure that adequate resources were channelled into key areas, and would arrange to recover its costs in whole or in part in sectors such as industry, where appropriate. It would also attract funds from non official sources, combining an intergovernmental mechanism with a mixture of public and private funds through co-financing.

"If the facility were both effectively managed and secure, it could attract, through co-financing, substantially greater levels of funding than are likely to become available from official sources alone. It would thus provide an important new source of support for a variety of critical links in the development process in many developing countries", says the UNDP.

Addressing a meeting of the development assistance committee of the Organization for Economic Co-operation and Development in Paris two weeks ago, $\mathrm{Mr}$ Bradford Morse, UNDP administrator, stressed the importance to developed and developing nations alike of a successful outcome to the UNCSTD conference, for substantive economic and political reasons.

He stated that the UNDP was prepared to upgrade its own scientific and technological activities in line with the general goals agreed by the conference. And he also suggested a possible scenario for agreement between UNCSTD delegates that would include

- The immediate provision of additional funds to support scientific and technological activities in developing countries;

- A committment by the developing countries to work out their most pressing needs in science and technology;

- A careful review of alternative financing mechanisms for meeting these needs, and how these could be built up; and

- Investigation of ways to ensure the adequate involvement of the scientific community in development efforts.

Speaking at a joint Senate and House hearing in Washington last week, Mrs Lucy Benson, US Undersecretary of State for Science and Technology, said that US negotiators at the UNCSTD preparatory committee meeting in New York last month had considered the Group of 77's proposal of a financing system was "somewhat unrealistic".

"We all feel that we will not be able to come up with what is considered an adequate sum of money" Mrs Benson told the congressional hearing. However, she said that members of the US UNCSTD delegation were waiting to hear more about the plans being discussed in the UN for a funding facility along the lines suggested by UNDP. and in particular were waiting for decisions to come out of the executive branch about the type of commitments that the US would have to make in Vienna. Ambassador Jean Wilkowskizn, US coordinator for UNCSTD, told the meeting that there was a suggestion within the UN that a new science and technology facility, if established, might "very much involve the Arab nations"'.

Officials in Washington last week confirmed that, in principle, those responsible for allocating aid funds within the US are sympathetic to some new type of facility being established for science and technology, particularly since it might parallel on an international basis the type of bilateral activities proposed for the Institute for Scientific and Technological Co-operation (whose fate, following its rejection by the Senate two weeks ago, still hangs in the balance).

The rationale for the ISTC has already been successfully argued for within the administration. On an international level, many may feel that a logical place for such a facility would be the UNDP. Much will depend, however on what type of financial commitment the administration feels that it is able to make in both the short and the long term.

Meanwhile, some speakers at the congressional hearing used the opportunity to express their frustration at the apparent lack of initiatives which the US seemed to be proposing to take at Vienna. "Our objectives for Vienna are fine, but the effort we proposed is scarcely commensurate, unless things change in the next few weeks", said William Carey, executive officer of the American Association for the Advancement of Science.

$\mathrm{Mr}$ Thomas Pickering of the State Department, however, told the hearing that the administration had been studying a wide range of possible initiatives, and was making a final selection of those it considered most feasible. Prime candidates are thought to be plans for resources monitoring satellite systems for developing countries (using technology developed by the National Aeronautics and Space Administration), a proposal to assist in setting up a global information network, and plans to link ISTC - if approved - to similar institutions in other developed countries.

Finally, asked whether the developed and developing nations were on the same wavelength as far as negotiations for UNCSTD were concerned, ambassador Wilkowski gave a frank appraisal of the situation. "It came as a shock to the National Academy of Sciences when it realised that this conference is not about science and technology but is political, because it deals with developing country concerns about inequality and dependence. Those are the catalytic forces which have to rise to this conference. It is the desire to overcome them which led to UNCSTD."

David Dickson 